\title{
Telephone-based anticoagulation management in the homebound setting: a retrospective observational study
}

This article was published in the following Dove Press journal:

International Journal of General Medicine

2 December 2013

Number of times this article has been viewed

\author{
Samer Hassan $1, *$ \\ Ali Naboush ${ }^{1, *}$ \\ Jared Radbel ${ }^{1, *}$ \\ Razan Asaad' \\ Homam Alkaied ${ }^{2}$ \\ Seleshi Demissie ${ }^{3}$ \\ Terenig Terjanian ${ }^{2}$ \\ 'Division of Internal Medicine, \\ ${ }^{2}$ Division of Hematology/Oncology, \\ ${ }^{3}$ Division of Statistics; Staten Island \\ University Hospital, Staten Island, \\ NY, USA \\ *These authors contributed equally to \\ this work
}

Background: Anticoagulation management is currently performed through anticoagulation clinics or self-managed with or without the help of medical services. Homebound patients are a unique population that cannot utilize anticoagulation clinics or self-testing. Telephone-based anticoagulation management could be an alternative to the traditional methods of monitoring warfarin in this subgroup. The objective of this retrospective, observational study is to investigate the feasibility of warfarin management in homebound patients.

Methods: This study was performed through the use of telephone-based adjustments of warfarin dose based on an international normalized ratio (INR) result. Four hundred forty-eight homebound patients referred to the anticoagulation clinic at Staten Island University Hospital were visited at home by a phlebotomist; a blood sample was drawn for initial laboratory testing. A nurse practitioner then called the patient or designated person to relay the INR result and to direct dosage adjustment. INR results and dosage changes were entered into an electronic medical record and analyzed statistically.

Results: The mean percentage of INR values in range was $58.39 \%$. The mean time when the INR was in the therapeutic range was $62.75 \%$. The percent of patients who were therapeutically controlled decreased as the number of medications increased. The complication rate was $4 \%$ per patient year, with an equal distribution between bleeding and clotting. These values compared favorably to other studies in which monitoring was performed through anticoagulation clinics or self-monitoring. The cost per visit at our anticoagulation clinic was found to be approximately $\$ 300$ compared with $\$ 82$ when utilizing our homebound service.

Conclusion: Telephone-based management of warfarin therapy in the homebound setting is feasible. It can lower the cost of health care expenditures compared to other modalities of anticoagulation management

Keywords: warfarin, anticoagulation, homebound, telephone-based, anticoagulation clinic, INR

\section{Introduction}

Warfarin has long been the drug of choice for the prevention and treatment of thromboembolic disorders. However, warfarin therapy is complicated by its narrow therapeutic index and fluctuations in the degree of anticoagulation. These fluctuations are caused by drug-drug interactions, drug-food interactions, changes in dietary intake of vitamin $\mathrm{K}$, and missed doses of warfarin during chronic therapy. ${ }^{1,2}$ The effectiveness of an anticoagulant is expressed as the normalized ratio (INR), the ratio of a patient's prothrombin time in seconds to a normal (control) sample, raised to the power determined by the type of analytical system employed. Despite management in specialized anticoagulation clinics, on average, a patient's INR is within the therapeutic
Correspondence: Terenig Terjanian Nalitt Institute of Cancer, 256 Mason Avenue, Staten Island, NY, USA

Tel + I 7186674700

Email tterjanian@siuh.edu 
range only $52 \%-66 \%$ of the time during warfarin therapy for a chronic condition; 3,4 this relatively low percentage can increase the risk for thromboembolism. ${ }^{5}$ Nonadherence to warfarin therapy is also a major contributor to subtherapeutic anticoagulation. ${ }^{6,7}$ Novel models of anticoagulation management have been instituted to address this issue. These methods range from management within an anticoagulation clinic to patient self-testing at home, with or without patient self-management.

Management of warfarin within an anticoagulation clinic (AC) can be through face-to-face appointments run by nurses or pharmacists or through telephone calls. Generally, using a telephone-based approach for the follow-up of patients has the benefit of decreasing costs. Spending is lowered by reducing the utilization of medical resources, including clinic visits, hospital admissions, lengths of stay, and intensive care unit (ICU) days. ${ }^{8}$ Specifically, when used in the anticoagulation clinic, this approach reduces the risk of anticoagulation therapy-related complications and is at least as effective as inperson visits to manage oral anticoagulation. ${ }^{9,10}$ Additionally, patients have reported a high degree of satisfaction. ${ }^{11}$

Self-management of oral anticoagulants is also effective because it improves the quality of oral anticoagulation, resulting in fewer thrombotic events and lower mortality. ${ }^{12,13}$ Unfortunately, self-monitoring is not feasible for all patients and requires the identification and education of suitable candidates who are physically and cognitively able to perform certain tasks. ${ }^{12,13}$ Factors associated with failure to perform these tasks include age, previous stroke history, poor cognition, and poor manual dexterity. ${ }^{14}$

Homebound is defined as those individuals with a condition resulting from surgery, illness, or injury that precludes them from accessing medical care outside the home. ${ }^{15}$ Homebound patients who need chronic anticoagulation would likely not be able to attend anticoagulation clinics, and most of them are not candidates for self-testing at home. ${ }^{14}$ To our knowledge, there are no clear guidelines on how to manage this population in a safe and efficient way. One proposed method to manage them is through home blood draws followed by telephone-based adjustments of INR levels. The purpose of this study is to assess the efficacy of telephone-based adjustments of warfarin in this unique homebound population.

\section{Patients and methods Study population}

The AC at Staten Island University Hospital (SIUH) is an outpatient program that was established for the purpose of managing and ensuring high quality care to patients requiring anticoagulation therapy. Nurse practitioners, in collaboration with their medical director, organize patient care. During their first visit, patients undergo initial assessment and are educated extensively about drug-drug interaction, use of herbals, and the importance of compliance to therapy. They are also asked to report any signs or symptoms of bleeding or thrombosis.

In the year 2000, a unique and dedicated service was established at the AC to serve homebound patients. When a homebound patient was referred to the AC, a phlebotomist made a home visit to draw a blood sample. This specimen was then sent to the main laboratory at SIUH for INR testing. A nurse practitioner would then call either the patient or a designated person on behalf of the patient. The call was designed to relay the INR result and direct dosage adjustment. The INR result and dosage change were entered into an electronic medical record and analyzed using CoagClinic ${ }^{\mathrm{TM}}$ software (Standing Stone Inc., Westport, CT, USA).

\section{Outcome variables}

The primary objective of the study was to assess the efficacy of telephone-based dose-adjustments of warfarin in homebound patients. This was assessed using the percentage of INR values in range ( $p I N R$ ), and the time in therapeutic range (tINR). The pINR was defined as the absolute number of INR values in the therapeutic range divided by the total number of INR values. The tINR was defined as the numbers of days where the INR was in the therapeutic range divided by the total number of days that the patient was followed. The secondary objective was to assess the effect of this modality on complications such as bleeding and thrombosis during anticoagulation. Both objectives were examined until stoppage of the treatment because of complications, death, or predetermined end of the study period. The minimal study period was 3 months.

\section{Study design}

We identified homebound patients who were on warfarin therapy using the CoagClinic software program during the period from January 1, 2000 to October 5, 2011. All patients who were on warfarin for less than 3 months were excluded. We collected all INR results for the patients included in the study over this period of time. Demographic data such as age, sex, and patient insurance type were also collected. Additionally, we collected data pertaining to the indication for anticoagulation, INR goal, duration of treatment, medical 
comorbidities, herbal and pharmacological medications, and complications of therapy.

Patients were subdivided based on certain characteristics. They were first stratified into six groups: $<75$ and $\geq 75$ year age groups, male or female groups, and INR goal of 2.5 or 3 groups. Patients were then also organized by indication for anticoagulation. For example, if they had atrial fibrillation and or atrial flutter they were placed into the Afib/Aflutter group. If they had had a deep venous thrombosis and or pulmonary embolism, they were placed into the DVT/PE group. If they had had a mitral valve or aortic valve replacement, they were placed into the MVR/AVR group. All other patients were placed into the "other indication" group. Patients were also divided into Medicare, Medicare/ private, private, and unknown insurance groups. They were also organized into three groups according to the number of medications $(0-4,5-7$, and $>7)$, three groups according to the number of comorbidities $(0-2,3-4,>4)$, and into two groups according to the absence or presence of herbal medications.

\section{Statistical methods}

The relationship between the outcome variables and demographic/clinical variables, such as age, sex, indication for treatment, number of medical comorbidities, and number of pharmacological and herbal medications were examined. For the purpose of statistical modeling, both pINR and tINR were transformed using an arscin transformation. As a first step, a univariate regression analysis was performed to evaluate the effect of each independent variable on the primary outcome variables. The factors found to be statistically significant at $P=0.15$ were entered into a multiple regression model. Significance tests for the final multiple regression models are based on type three sum-of-squares, using two-sided tests at the 0.05 level. The analyses were implemented using SAS Version 9.3 (SAS Institute, Inc., Cary, NC, USA).

\section{Results}

\section{Baseline characteristics}

We identified 448 homebound patients from January 1, 2000 to October 5, 2011. We excluded 42 patients who were on warfarin for less than 3 months; for a complete list of baseline characteristics, see Table 1 . There were 267 females (66.42\%) compared to 135 males. There were 247 aged $\geq 75$ years $(62.85 \%)$ compared to 146 aged $<75$ years. When subdivided further, the majority of the patients fell into the 75 - to 85 -year age-group $(n=190,51.34 \%)$ followed by the 65 - to
Table I Baseline demographics

\begin{tabular}{|c|c|}
\hline Demographics & n (\%) \\
\hline \multicolumn{2}{|l|}{ Age, years } \\
\hline$<75$ & $146(37.15)$ \\
\hline$\geq 75$ & $247(62.85)$ \\
\hline \multicolumn{2}{|l|}{ Sex } \\
\hline Male & $135(33.58)$ \\
\hline Female & $267(66.4)$ \\
\hline \multicolumn{2}{|l|}{ INR goal } \\
\hline 2.5 & $359(88.65)$ \\
\hline 3 & $45(11.14)$ \\
\hline \multicolumn{2}{|l|}{ Insurance type } \\
\hline Medicare & $143(35.4)$ \\
\hline Medicare/private & 46 (II.39) \\
\hline Private & $34(8.42)$ \\
\hline Unknown & I8I (44.8) \\
\hline \multicolumn{2}{|l|}{ Indication to treat } \\
\hline Afib/Aflutter & $229(57.97)$ \\
\hline DVT/PE & III (28.I) \\
\hline MVR/AVR & $42(10.63)$ \\
\hline Other & $13(3.29)$ \\
\hline \multicolumn{2}{|l|}{ Comorbidities } \\
\hline $0-2$ & 115 (29.26) \\
\hline $3-4$ & I 32 (33.59) \\
\hline$>4$ & $146(37.15)$ \\
\hline \multicolumn{2}{|l|}{ Medications } \\
\hline $0-4$ & I 32 (33.42) \\
\hline $5-7$ & $136(34.43)$ \\
\hline$>7$ & $127(32.15)$ \\
\hline \multicolumn{2}{|l|}{ Herbals } \\
\hline 0 & 244 (62.09) \\
\hline$\geq 1$ & 149 (37.91) \\
\hline
\end{tabular}

Abbreviations: $\mathrm{n}$, number; INR, international normalized ratio; Afib/Aflutter, atrial fibrillation/flutter; DVT/PE, deep vein thrombosis/pulmonary embolism; MVR/AVR, mitral/aortic valve replacement.

75 -year age-group $(\mathrm{n}=111,24.33 \%)$, the $>85$ year age-group $(n=57,14.51 \%)$, and the $<65$ age-group $(n=48,9.76 \%)$. The most common insurance was Medicare $(n=143,35.4 \%)$, followed by private/Medicare $(n=46,11.39 \%)$ and private $(\mathrm{n}=34,8.42 \%)$. However, $181(44.8 \%)$ patients did not have insurance documented in the electronic system.

The most common mean INR goal was $2.5 \quad(n=359$, $88.65 \%)$ versus $3(n=45)$. Patients with an INR goal of 2.5 were mostly older than $75(n=228,65.1 \%)$ compared with patients younger than $75(\mathrm{n}=122)$. In contrast, those with INR goal of 3 were mostly younger than 75 ( $n=26,57.8 \%)$ compared with people at least 75 years of age $(n=19, P=0.0028)$. The most common indication for anticoagulation was Afib/ Aflutter ( $n=229,57.97 \%)$ followed by DVT/PE $(n=111$, $28.1 \%), M V R / A V R(n=42,10.63 \%)$, and other conditions $(n=13,3.29 \%)$. Patients with Afib/Aflutter $(n=161,40.76 \%)$ and DVT/PE $(\mathrm{n}=62,15.7 \%)$ were mostly older than 75 years $(P=0.001)$. 


\section{Outcomes}

The mean percentage of INR results in the pINR for all patients was $58.39 \%( \pm 13.96 \%)$ ranging from a minimum of $13.33 \%$ to a maximum of $100 \%$; Table 2 lists pINR by subgroup. The pINR was greater in patients with INR goal of 2.5 and was $59.23 \%$ compared with $51.74 \%$ in patients with an INR goal of $3(P=0.009)$. Patients with Afib/A flutter had the greatest pINR (60.26\%) followed by the DVT/PE group $(57.76 \%)$ and then the AVR/MVR group $(51.09 \%)(P=0.0014)$. There was no statistical difference in pINR based on age, number of medications, number of herbals, number of comorbidities, insurance type, or sex. Upon multiple regression analysis, the number of medications correlated with pINR $(P=0.04)$, whereas INR goal and indication treat did not.

The mean treatment duration was 44.21 months. The mean tINR was $62.75 \%( \pm 16.32 \%)$, ranging from a minimum

Table 2 pINR and tINR according to patient demographics

\begin{tabular}{|c|c|c|c|c|}
\hline & $\begin{array}{l}\text { Mean } \\
\text { pINR (\%) }\end{array}$ & $P$-value & $\begin{array}{l}\text { Mean } \\
\text { tINR (\%) }\end{array}$ & $P$-value \\
\hline \multicolumn{5}{|l|}{ Age } \\
\hline$\geq 75$ & 59.3 & 0.33 & 63.73 & 0.31 \\
\hline$<75$ & 56.9 & & 61.24 & \\
\hline \multicolumn{5}{|l|}{ Sex } \\
\hline Male & 57.68 & 0.3387 & 62.84 & 0.823 \\
\hline Female & 58.86 & & 62.56 & \\
\hline \multicolumn{5}{|l|}{ INR goal } \\
\hline 2.5 & 59.2 & 0.009 & 63.3 & 0.049 \\
\hline 3 & 51.7 & & 58.34 & \\
\hline \multicolumn{5}{|l|}{ Insurance type } \\
\hline Medicare & 59.7 & 0.49 & 62.25 & $0.68 I$ \\
\hline Medicare/private & 59.4 & & 65.64 & \\
\hline Private & 58.2 & & 61.87 & \\
\hline Unknown & 57.1 & & 64.84 & \\
\hline \multicolumn{5}{|l|}{ Indication to treat } \\
\hline Afib/Aflutter & 60.3 & 0.0014 & 64.49 & $0.07 I$ \\
\hline DVT/PE & 57.8 & & 61.19 & \\
\hline MVR/AVR & 51.2 & & 57.74 & \\
\hline Other & 54.3 & & 61.36 & \\
\hline \multicolumn{5}{|l|}{ Comorbidities } \\
\hline $0-2$ & 56.3 & 0.233 & 61.39 & 0.475 \\
\hline $3-4$ & 59.63 & & 62.56 & \\
\hline$>4$ & 58.86 & & 63.91 & \\
\hline \multicolumn{5}{|l|}{ Medications } \\
\hline $0-4$ & 57.93 & 0.145 & 62.76 & 0.993 \\
\hline $5-7$ & 60.16 & & 62.82 & \\
\hline$>7$ & 57.01 & & 62.68 & \\
\hline \multicolumn{5}{|l|}{ Herbals } \\
\hline 0 & 57.91 & 0.224 & 62.19 & 0.274 \\
\hline$\geq 1$ & 59.69 & & 63.77 & \\
\hline
\end{tabular}

Abbreviations: INR, international normalized ratio; pINR, percentage of INR values in range; tINR, time of INR in therapeutic range; Afib/Aflutter, atrial fibrillation/flutter; DVT/PE, deep vein thrombosis/pulmonary embolism; MVR/AVR, mitral/aortic valve replacement. of $4.17 \%$ to a maximum of $100 \%$; Table 2 lists the tINR by subgroup. The tINR was $63.3 \%$ for patients with an INR goal of 2.5 compared with $58.34 \%$ in the INR goal of the 3 group $(P=0.049)$. The Afib/Aflutter group had the highest tINR (64.49\%), followed by DVT/PE group (61.19\%), and the AVR/ MVR Group (57.74\%) ( $P=0.07)$. There was no statistical difference in tINR in the age, number of medications, number of herbals, number of comorbidities, insurance type, or sex groups. The multiple regression analysis did not show any significant association between any risk factor and the tINR variable.

\section{Complications}

The complication rate (complications/patients followed) was $15.35 \%(n=61)$. The complication rate per patient year was $4 \%$. When subdividing the complications, there was an equal distribution between bleeding $(\mathrm{n}=31,7.67 \%)$ and clotting $(\mathrm{n}=30,7.67 \%)$; Table 3 lists complications

Table 3 Total complications per patient demographics

\begin{tabular}{|c|c|c|c|}
\hline & $\begin{array}{l}\text { Complications } \\
\text { n (\%) }\end{array}$ & $\begin{array}{l}\text { Without } \\
\text { complications } \\
\text { n (\%) }\end{array}$ & $P$-value \\
\hline \multicolumn{4}{|l|}{ Age, years } \\
\hline$\geq 75$ & $40(10.13)$ & $207(52.4 I)$ & 0.5935 \\
\hline$<75$ & $21(5.32)$ & $127(32.15)$ & \\
\hline \multicolumn{4}{|l|}{ Sex } \\
\hline Male & I8 (4.48) & $117(29.10)$ & 0.4095 \\
\hline Female & $44(10.95)$ & $223(55.47)$ & \\
\hline \multicolumn{4}{|l|}{ INR goal } \\
\hline 2.5 & $53(13.12)$ & $306(75.74)$ & 0.358 \\
\hline 3 & $9(2.23)$ & $36(8.91)$ & \\
\hline \multicolumn{4}{|l|}{ Insurance type } \\
\hline Medicare & 14 (3.47) & $129(31.93)$ & 0.0474 \\
\hline Medicare/private & $12(2.97)$ & $34(8.42)$ & \\
\hline Private & $5(1.24)$ & $34(8.42)$ & \\
\hline Unknown & 31 (7.67) & $150(37.13)$ & \\
\hline \multicolumn{4}{|l|}{ Indication to treat } \\
\hline Afib/Aflutter & $43(10.64)$ & 191 (47.28) & 0.0282 \\
\hline $\mathrm{DVT} / \mathrm{PE}$ & $8(1.98)$ & 107 (26.49) & \\
\hline MVR/AVR & $9(2.23)$ & $33(8.17)$ & \\
\hline Other & $2(0.50)$ & II (2.72) & \\
\hline \multicolumn{4}{|l|}{ Comorbidities } \\
\hline $0-2$ & II (2.74) & $105(26.12)$ & 0.0550 \\
\hline $3-4$ & $20(4.98)$ & $117(29.10)$ & \\
\hline$>4$ & $30(7.46)$ & $119(29.60)$ & \\
\hline \multicolumn{4}{|l|}{ Medications } \\
\hline $0-4$ & $10(2.48)$ & $124(30.69)$ & 0.0081 \\
\hline $5-7$ & $26(6.44)$ & $112(27.72)$ & \\
\hline$>7$ & $26(6.44)$ & $106(26.24)$ & \\
\hline \multicolumn{4}{|l|}{ Herbals } \\
\hline 0 & $30(7.46)$ & 221 (54.98) & 0.0130 \\
\hline$\geq 1$ & $32(7.96)$ & $119(29.60)$ & \\
\hline
\end{tabular}

Abbreviations: $n$, number; INR, international normalized ratio; Afib/Aflutter, atrial fibrillation/flutter; DVT/PE, deep vein thrombosis/pulmonary embolism; MVR/AVR, mitral/aortic valve replacement. 
per patient subgroup. The highest complication rate was in the Afib/flutter group ( $\mathrm{n}=43,10.64 \%)$, followed by the AVR/MVR group $(n=9,2.23 \%)$ and the DVT/PE group $(\mathrm{n}=8,1.98 \%)(P<0.028)$. The highest complication rate by insurance carrier was the unknown group $(n=31,7.67 \%)$, followed by the Medicare group ( $\mathrm{n}=14,3.47 \%)$, private/ Medicare group $(\mathrm{n}=12,2.97 \%)$, and the private group $(\mathrm{n}=5$, $1.24 \%)(P<0.04)$.

Patients taking zero to four medications had a complication rate of $2.48 \%(\mathrm{n}=10)$ compared with $6.44 \%(\mathrm{n}=26)$ for patients on five to seven medications, and $6.44 \%(n=26)$ for patients taking more than seven medications $(P=0.0081)$. Patients with zero to two comorbidities had a complication rate of $2.74 \%(n=11)$, compared with $4.98 \%(n=20)$ in patients with three to four comorbidities, and $7.46 \%(\mathrm{n}=30)$ in patients with five or more co-morbidities $(P=0.055)$. Patients who were not taking any herbal medications had a complication rate of $7.46 \%(n=30)$ compared with $7.96 \%(n=32)$ in patients on herbal medications $(P=0.013)$.

There was no statistical difference in complications based on age, sex, and INR goal. In addition, there was no statistical difference between clotting and bleeding according to the age, number of medications, number of comorbidities, sex, insurance type, indication to treat, INR goal, or the number of herbal medications (Table 4). Multiple regression analysis revealed that insurance type was the only independent variable that correlated with complication rate $(P=0.09)$.

\section{Discussion $\mathrm{pINR/tINR}$}

Overall, homebound patients were kept in the correct INR range at a mean of $58.4 \%$. These patients performed quite well compared with prior studies that report a range of $51 \%-64 \%$ of INR values in the INR range for patients being monitored in an anticoagulation clinic. ${ }^{4,16}$ Homebound patients in our study also spent $62.75 \%$ of their time in the INR. This value also equates well to a systematic review of 67 studies that compared the time in the INR range among community practices, anticoagulation clinics, and clinical trials where patients were therapeutic $63.6 \%$ of the time. ${ }^{17}$ Moreover, patients' time in the INR range was only $50 \%$ in the community setting when the self-management group was excluded. ${ }^{17}$ Thus, monitoring homebound patients with telephone-based management may be as effective or superior to other community-based surveillance modalities.

Upon subdividing our patient pool, the univariate analysis revealed that only the INR goal and indication to treat groups were significantly related to the pINR endpoint variable.
Table 4 Bleeding and clotting according to patient demographics

\begin{tabular}{|c|c|c|c|}
\hline & $\begin{array}{l}\text { Bleeding } \\
\text { n (\%) }\end{array}$ & $\begin{array}{l}\text { Clotting } \\
\text { n (\%) }\end{array}$ & $P$-value \\
\hline \multicolumn{4}{|l|}{ Age } \\
\hline$\geq 75$ & $23(37.70)$ & 17 (27.87) & 0.1498 \\
\hline$<75$ & $8(13.11)$ & $13(2|.3|)$ & \\
\hline \multicolumn{4}{|l|}{ Sex } \\
\hline Male & 7 (II.29) & II (I7.74) & 0.2631 \\
\hline Female & $24(38.7 I)$ & $20(32.26)$ & \\
\hline \multicolumn{4}{|l|}{ INR goal } \\
\hline 2.5 & $25(6.19)$ & $28(6.93)$ & 0.314 \\
\hline 3 & $6(1.49)$ & $3(0.74)$ & \\
\hline \multicolumn{4}{|l|}{ Insurance type } \\
\hline Medicare & $9(14.52)$ & $5(8.06)$ & 0.2064 \\
\hline Medicare/private & $4(6.45)$ & $8(12.90)$ & \\
\hline Private & $\mathrm{I}(\mathrm{I} .6 \mathrm{I})$ & $4(6.45)$ & \\
\hline Unknown & $17(27.4) 2$ & $14(22.58)$ & \\
\hline \multicolumn{4}{|l|}{ Indication to treat } \\
\hline Afib/Aflutter & 21 (33.87) & $22(35.48)$ & 0.6769 \\
\hline DVT/PE & $3(4.84)$ & $5(8.06)$ & \\
\hline MVR/AVR & $6(9.68)$ & $3(4.84)$ & \\
\hline Other & I (I.6I) & I (I.6I) & \\
\hline \multicolumn{4}{|l|}{ Comorbidities } \\
\hline $0-2$ & $8(13.11)$ & $3(4.92)$ & 0.2242 \\
\hline $3-4$ & $9(14.75)$ & II (18.03) & \\
\hline$>4$ & $13(2|.3|)$ & $17(27.87)$ & \\
\hline \multicolumn{4}{|l|}{ Medications } \\
\hline $0-4$ & $6(9.68)$ & $4(6.45)$ & 0.7581 \\
\hline $5-7$ & I3 (20.97) & I3 (20.97) & \\
\hline$>7$ & $12(19.35)$ & $14(22.58)$ & \\
\hline \multicolumn{4}{|l|}{ Herbals } \\
\hline 0 & $17(27.42)$ & $13(20.97)$ & 0.3094 \\
\hline$\geq 1$ & $14(22.58)$ & $18(29.03)$ & \\
\hline
\end{tabular}

Abbreviations: $n$, number; INR, international normalized ratio; Afib/Aflutter, atrial fibrillation/flutter; DVT/PE, deep vein thrombosis/pulmonary embolism; MVR/AVR, mitral/aortic valve replacement.

The INR goal was achieved more in the patients with an INR goal of 2.5 compared to the group with an INR goal of 3 $(P=0.009)$. However, the samples sizes of these two groups were not balanced. Patients with Afib/Aflutter had more INR values in range followed by the DVT/PE group and the AVR/MVR group $(P=0.0014)$. This is probably due to the fact that the duration of treatment of the Afib/Aflutter group was longer than the others. Thus, the registered nurses may have had more experience and knowledge about how to control these patients' INR levels. It is also possible that the length of exposure to warfarin itself may have contributed to the differences in controlling INR levels. In any event, these two variables were not found to be significant upon multiple regression analysis. Upon univariate analysis of tINR, the INR goal of 2.5 was once again found to be better controlled. However, when entered into the multiple regression analysis this variable was not found to have a significant relationship to tINR. 
The only variable found to have a significant relationship to INR monitoring after multiple regression analysis was the number of medications. In this respect, patients taking five to seven medications had a greater pINR than patients taking more than seven medications. Understandably, the more medications a patient takes the more opportunity there is for drug-warfarin interaction. However, this cofactor to INR monitoring is not exclusive to homebound monitoring.

\section{Complications}

The complication rate in our homebound patient population was $15.35 \%$, with an equal distribution among bleeding and clotting. The complication rate per patient year was $4 \%$. Three retrospective and two prospective cohort studies have reported event rates between $6.2 \%$ and $8.1 \%$ per patient year for patients being monitored in anticoagulation centers. ${ }^{3}$ Thus, our patient population had fewer complications than patients in prior studies that were monitored in traditional anticoagulation centers.

In the univariate analysis, there was a significant difference in the complication rate among the indications to treat, number of medications, number of herbal medications, and insurance carriers. This correlation may not be directly related to the warfarin effect. According to our multiple regression analysis, the INR level was similarly controlled in all patient groups regardless of the INR goal, the number of medical comorbidities, and the intake of herbal products. This could be partially explained by warfarin-drug interactions in patients taking more than seven medications. Regardless, all of these groups failed to show significance upon multiple regression analysis except the insurance-carrier group. However, this was a weak association, given that only $55.2 \%$ of our patients had an identifiable insurance in the CoagClinic software.

\section{Advantages of homebound monitoring}

A potential benefit of homebound monitoring of patients is a reduction in health care expenditures. The charge of an initial visit at the SIUH anticoagulation clinic is on average $\$ 309$. The charge for a follow-up visit is $\$ 298$. Patients under the homebound service are charged $\$ 15$ for a resultant INR and only $\$ 67$ for the travel expenses of the phlebotomist and venipuncture. The only additional potential expense would be payment for a registered nurse to interpret the results and call the patient to adjust dosing. However, this expenditure could easily be compensated by the potential savings from preventing hospital readmissions secondary to bleeding and thrombosis. In addition, it would eliminate other ancillary costs such as patient transportation.

\section{Strengths and limitations of the study}

We were able to draw our patient pool from one of the largest anticoagulation centers in the United States that has a well-organized electronic data collection system. In addition, all of our patients were managed through the same central system, eliminating biases from varying centers' methods of management.

However, our study did not have a control group and was subject to the same biases found in all retrospective studies, which include selection bias, information bias, missing or incomplete records, and most importantly, compliance of patients to treatment. In addition, given the age of the clientele, hearing loss may have compromised patient compliance with treatment schedule.

\section{Conclusion}

Homebound testing is a feasible modality for outpatient INR monitoring. To our knowledge, this is the first study ever to look into the efficacy of telephone-based adjustments of warfarin in homebound patients. Our homebound monitoring compared very well to prior monitoring studies, which took place in an anticoagulation clinic. It is even effective in monitoring high-risk patients. In addition, homebound monitoring has the added benefit of cutting health care expenditures for INR monitoring.

\section{Disclosure}

No external funding, apart from the support of the authors' institution, was available for this study. All authors report that there are no conflicts of interest in this work. All authors had access to the data, and each author had a role in writing the manuscript.

\section{References}

1. Reynolds MW, Fahrbach K, Hauch O, et al. Warfarin anticoagulation and outcomes in patients with atrial fibrillation: a systematic review and metaanalysis. Chest. 2004;126(6):1938-1945.

2. Hylek EM, Evans-Molina C, Shea C, Henault LE, Regan S. Major hemorrhage and tolerability of warfarin in the first year of therapy among elderly patients with atrial fibrillation. Circulation. 2007;115(21):2689-2696.

3. Ansell J, Hirsh J, Hylek E, Jacobson A, Crowther M, Palareti G. Pharmacology and Management of the Vitamin K Antagonists: American College of Chest Physicians Evidence-Based Clinical Practice Guidelines. 8th ed. Chest. 2008;133(Suppl 6):160S-198S.

4. Wittkowsky AK, Devine EB. Frequency and causes of overanticoagulation and underanticoagulation in patients treated with warfarin. Pharmacotherapy. 2004;24(10):1311-1316.

5. Hylek EM, Go AS, Chang Y, et al. Effect of intensity of oral anticoagulation on stroke severity and mortality in atrial fibrillation. New Engl J Med. 2003;349(11):1019-1026. 
6. Cavallari LH, Aston JL, Momary KM, Shapiro NL, Patel SR, Nutescu EA. Predictors of unstable anticoagulation in African Americans. J Thromb Thrombolys. 2009;27(4):430-437.

7. Palareti G, Legnani C, Guazzaloca G, et al. Risks factors for highly unstable response to oral anticoagulation: a case-control study; ad hoc Study Group of the Italian Federation of Anticoagulation Clinics. Brit J Haematol. 2005;129(1):72-78.

8. Wasson J, Gaudette C, Whaley F, Sauvigne A, Baribeau P, Welch HG. Telephone care as a substitute for routine clinic follow-up. JAMA. 1992;267(13):1788-1793.

9. Witt DM, Sadler MA, Shanahan RL, Mazzoli G, Tillman DJ. Effect of a centralized clinical pharmacy anticoagulation service on the outcomes of anticoagulation therapy. Chest. 2005;127(5):1515-1522.

10. Wittkowsky AK, Nutescu EA, Blackburn J, et al. Outcomes of oral anticoagulant therapy managed by telephone vs in-office visits in an anticoagulation clinic setting. Chest. 2006;130(5):1385-1389.

11. Waterman AD, Banet G, Milligan PE, et al. Patient and physician satisfaction with a telephone-based anticoagulation service. J Gen Intern Med. 2001;16(7):460-463.

12. Christensen TD, Johnsen SP, Hjortdal VE, Hasenkam JM. Selfmanagement of oral anticoagulant therapy: a systematic review and meta-analysis. Int J Cardiol. 2007;118(1):54-61.
13. Heneghan C, Alonso-Coello P, Garcia-Alamino JM, Perera R, Meats E, Glasziou P. Self-monitoring of oral anticoagulation: a systematic review and meta-analysis. Lancet. 2006;367(9508):404-411.

14. Dolor RJ, Ruybalid RL, Uyeda L, et al. An evaluation of patient self-testing competency of prothrombin time for managing anticoagulation: prerandomization results of VA Cooperative Study \#481 - The Home INR Study (THINRS). J Thromb Thrombolysis. 2010;30(3):263-275.

15. Sections 501-508 of the Medicare, Medicaid, and SCHIP Benefits Improvement and Protection Act of 2000 (BIPA). US House of Representatives. Available from: http:/www.govtrack.us/congress/ bills/106/hr5661/text. Accessed September 27, 2013.

16. Chiquette E, Amato MG, Bussey HI. Comparison of an anticoagulation clinic with usual medical care: anticoagulation control, patient outcomes, and health care costs. Arch Intern Med. 1998;158(15):1641-1647.

17. van Walraven C, Jennings A, Oake N, Fergusson D, Forster AJ. Effect of study setting on anticoagulation control: a systematic review and metaregression. Chest. 2006;129(5):1155-1166.
International Journal of General Medicine

\section{Publish your work in this journal}

The International Journal of General Medicine is an international, peer-reviewed open-access journal that focuses on general and internal medicine, pathogenesis, epidemiology, diagnosis, monitoring and treatment protocols. The journal is characterized by the rapid reporting of reviews, original research and clinical studies across all disease areas.

\section{Dovepress}

A key focus is the elucidation of disease processes and management protocols resulting in improved outcomes for the patient.The manuscript management system is completely online and includes a very quick and fair peer-review system. Visit http://www.dovepress.com/ testimonials.php to read real quotes from published authors.

Submit your manuscript here: http://www.dovepress.com/international-journal-of-general-medicine-journal 